\title{
Piritrexim Isethionate
}

National Cancer Institute

\section{Source}

National Cancer Institute. Piritrexim Isethionate. NCI Thesaurus. Code C91407.

The isethionate salt of piritrexim, a synthetic antifolate agent with antiparasitic, antipsoriatic and antitumor properties. Piritrexim inhibits the enzyme dihydrofolate reductase enzyme, thereby disrupting folate metabolism and DNA synthesis and cell division. 